\title{
KABLOSUZ SENSÖR AĞLARINDA KÜÇÜLTÜLMÜŞ RADYO HARİTASI KULLANAN İMZA TABANLI DİNAMİK KONUM BULMA TEKNİĞİ
}

\author{
Yetkin TATAR*, Güngör YILDIRIM** \\ *Bilgisayar Müh. Böl., Mühendislik Fakültesi, Firat Üniversitesi, Elazığ \\ ${ }^{* * *}$ D.S.İ. IX. Bölge Müdürlüğü, Elazı ̆ \\ vtatar@firat.edu.tr, gyildirim@dsi.gov.tr
}

(Geliş/Received: 13.05.2013; Kabul/Accepted: 20.03.2014)

\begin{abstract}
ÖZET
Kapalı alanlarda konum tespiti için kullanılan algoritmalardan birisi de kablosuz sensör ağlarında da kullanılan "İmza" veya "Parmak izi (Fingerprint)" tabanlı konum tespiti algoritmasıdır. İmza tabanlı konum tespiti," Alınan Sinyal Gücü Göstergesi (RSSI)" radyo haritalama ve konum kestirim fazlarından oluşur. Haritalama fazında, elde edilen RSSI veritabanının küçük kapasiteli fakat çalışılacak alandaki RSSI dağılımını iyi ifade edebilecek yapıda olması, konum tespiti fazında ise kestirimin doğruluk miktarı ve hesaplama hızı önemli kriterlerdir. $\mathrm{Bu}$ çalışmada kapalı alanlardaki kablosuz sensör ağ ortamlarında kullanılabilen, imza tabanlı konum tespiti yöntemi için iki yeni yaklaşım önerilmiştir. İlk yaklaşım, radyo haritalama fazında, "K-Means" metodunu kullanarak her bir çapa düğüme ait RSSI verilerinin ayrı ayrı indirgenip ilgili radyo haritasının boyutunun küçültülmesini sağlayan bir tekniktir. Ayrıca bu fazda konum kestirimi işleminin hassasiyetini arttırmak için "Mantıksal Alt Bölgeleme" işlemi gerçekleştirilmiştir. İkinci yaklaşım ise; konum kestirimi fazı için K-En Yakın Komşuluk (KNN) yöntemine alternatif olabilecek, karar için sabit bir "K" değerinin yerine, bu değerin mantıksal alt bölgelemedeki karar hücre sayısına göre dinamik olarak seçildiği bir tekniktir. Sistem kapalı bir ortamda TelosB düğümlerle gerçekleştirilerek, önerilen yaklaşımlara göre hesapsal ve deneysel sonuçlar elde edilmiştir. Bunun yanı sıra literatürde karar tabanlı yaklaşım olarak bilinen KNN temelli lokasyon tespit algoritması da mevcut test ortamına uygulanarak deneysel ve hesapsal sonuçları elde edilmiştir. Buradan elde edilen sonuçlar ile önerilen tekniğin sonuçları karşılaştırılarak önerilen tekniğin daha uygun olduğu test edilmiş̧ir.
\end{abstract}

Anahtar Kelimeler: Konum Bulma, Kablosuz Sensör Ağları, İmza Tabanı

\section{A DYNAMIC LOCATION ESTIMATION TECHNIQUE BASED ON FINGERPRINT USING A REDUCED RADIO MAP IN WIRELESS SENSOR NETWORKS}

\begin{abstract}
In closed areas, fingerprint location estimation algorithms using a radio map, which can be used in wireless sensor networks, consist of two phases, mapping and location estimation. There are several important criterions in the phases, for example using of a radio map which has a small capacity and which shows a comprehensive RSSI dispersion, a quick position calculation, a good accuracy rate, and so on. In the study, a novel technique which employs K-Means method to decrease size of the radio map by reducing separately RSSI (Received Signal Strength Indicator) data of the anchors has been proposed for indoor position detection in WSNs. Besides, a subfield construction process to increase the accuracy of the estimation has been carried out. In the location estimation phase, a technique which is different from K-Nearest Neighbour (KNN) has been preferred. In this technique, unlike KNN the number of the decision cells varies dynamically according to RSSI data received. The system was implemented in a closed environment by using TELOSB nodes. The results of the experiments and the calculations were compared with the results of well-known deterministic methods based on KNN and the validation of the proposed system was tested.
\end{abstract}

Keywords: Localization, Wireless Sensor Networks, Fingerprint 


\section{GIRIŞ̧ (INTRODUCTION)}

Kablosuz Sensör Ağlarının (WSN) önemli kullanım alanlarından birisi de kapalı veya açık ortamlarda arama kurtarma, afet yardımı, hedef izleme, lokasyon bazında klimatik bilgi edinme gibi birçok önemli fonksiyonun temelini oluşturan konum bulma veya lokasyon tespiti üzerinedir. Kapalı alanlarda, bina duvar ve dış yüzeylerinin sebep olduğu sinyal zayıflamasından dolayı GPS kullanımı etkisiz kaldığından, konum bulma sistemlerinde WSN gibi farklı kablosuz haberleşme teknolojilerden faydalanılabilinir. "Lokal Pozisyonlama Sistemleri" de denilen kablosuz teknoloji temelli konum tespiti sistemlerini geliştirmek için araştırmalar artarak sürmektedir $[1,2]$.

WSN'lerde referans nokta temelli konum tespiti; koordinatları önceden belirlenmiş noktalara konulan sabit sensör düğümlere (beacon, çapa) göre, bir mobil düğümün (hedef düğüm) koordinatlarının belirlenmesi işlemidir. Kısa-mesafe Radyo Sinyalini (RF) kullanan lokasyon belirleme metotları, konum bulma uygulamalarında sıkça kullanılmaktadır. RF temelli konum bulma metotları, "Yön-Bulma" ve "Mesafe-Bulma" temelli olarak iki ana kategoriye ayrılır. Mesafe-Bulma temelli konum tespitinde sabit sensör düğümler ile mobil düğüm arasındaki uzaklıklar sıklıkla Alınan Sinyal Gücü ölçümüyle hesaplanır [1,3-5]. Günümüzde pek çok kablosuz sensör dügüum donanımında var olan RSSI (Received Signal Strength Indicator - Alınan Sinyal Gücü Göstergesi) okuyabilme özelliğinden dolayı, lokasyon tespiti algoritmalarının birçoğunda RSSI-mesafe ilişkisine dayalı teknikler tercih edilmektedir [6]. Ölçülen RSSI değerini ve RADAR tekniğini [7] kullanarak lokasyon kestirimi yapan önemli yöntemlerden birisi de, "imza tabanlı yöntem" olarakta isimlendirilebilen fingerprint (imza tabanı / parmakizi) yöntemidir. Bu yöntem iki fazdan oluşur. Birincisi mevcut alanda belirlenmiş noktalar için, sabit düğümlerden alınan RSSI değerlerinin (imza veya fingerprint) saklandığı bir veritabanı oluşturma işlemidir. Buna off-line fazı veya RSSI haritalama fazı da denir. İkinci faz ise mobil düğümün, sabit dügüumlerden on-line olarak ölçtüğü RSSI değerleri ile veritabanındaki verilerin (imza değerlerinin) etkileştirilerek konum tespiti işlemidir [8]. Buna online veya konum (lokasyon) tahmin fazı da denilmektedir. $\mathrm{Bu}$ fazda konum tespiti için karar tabanlı, olasılık tabanlı ve yumuşak hesaplama metotları kullanılabilmektedir. [9].

RSSI tabanlı fingerprint tekniğinde; konum tespitinin doğruluk performansı; hesaplama hızı, sensör düğümlerin hafizalama ve hesaplama kapasiteleri, enerji verimleri, RSSI değerinin ölçüm zorluğu, ortamın bozucu etkisi, az sayıda sabit düğüm kullanılması gibi bir takım faktörler göz önüne alınarak gerek RSSI harita oluşturma gerekse konum kestirimi fazları için değişik çözümler üretilebilir. Örneğin; alanda ölçme zorluğu olmayan ve veritabanı boyutunun kritik olmadığı uygulamalarda, haritalama fazında, fazla sayıda RSSI ölçüm sonucunda elle oluşturulan veri tabanı, konum bulma hassasiyetini arttırabilir. Buna karşılık az sayıda RSSI ölçümü ve tahmin algoritmaları kullanılarak küçük boyutlu veri tabanının geliştirilmesi de önemli bir çözüm olabilir. Çünkü radyo haritası veritabanının boyutu doğrudan doğruya işlemcinin hesaplama ve iletişim yüküyle doğru orantılıdır [10]. Fingerprint yönteminde, gerek haritalama fazı gerekse konum tespit fazları için birçok çalışmalar yapılmış olup halen devam eden araştırmalar da vardır [7-9,11-18]. Bunlardan radyo haritalama fazı için yapılan bir çalışmada ölçüm zorluğu olan mekanlar için, az sayıda ölçüm ve ortalama yol-kaybına dayalı, tek-eğimli RSSI tahmin modeli kullanılarak, mekandaki değişik noktaları kapsamak üzere genişletilmiş RSSI haritalama veritabanının oluşturulduğu bir yöntem önerilmiştir [8]. Benzer bir çalışmada ise az sayıda RSSI örnek değeri ile Weibull dağılım fonksiyonunun parametrelerinin tahmin edilmesiyle, alandaki belirli noktaları kapsayan genişletilmiş bir RSSI haritalama modeli önerilmiştir [14]. Diğer bir çalışmada da WLAN'lar için, fingerprint tekniğinde ağırlık faktörüne dayalı bir yapının daha dinamik bir veritabanı oluşumuna imkan verebileceği savunulmuştur [9]. Başka bir çalışmada ise, GSM ortamlarında konum bulma sürecindeki radyo haritalama veritabanının küçültülmesi için BWC (Block-based Weighted Clustering) ismiyle bilinen ve ağırlık varyantlı K-means yapısından türetilen yeni bir kümeleme formu, geliştirilerek GSM ağlarda denenmiş ve kendi sınıfındaki yöntemlerden daha başarılı olduğu belirtilmiştir [19]. WLAN sistemlerde radyo haritası içinde alt bölgeler oluşturarak, konum tespiti fazında mobil düğümün hangi alt bölgede olduğunu KNN (K-Nearest Neighbor, K-en yakın komşuluk) metodu ile bulan bir başka çalışmada ise, bu yöntemle konum tespiti hata oranlarının bir miktar azaldığı belirtilmiștir. [20]. Fingerprint temelli konum bulma yönteminde, on-line fazındaki çözümlerin seçiminde ise kullanılacak hesaplama platformu (merkezi bilgisayar, sensör düğ̈̈m vb) ve lokalizasyonun doğruluk seviyesi, önemli parametrelerden bazılarıdır [2,4,21]. Bu konuda yapılan çalışmaların birinde, kapalı ortamda konum bulma tekniklerinden "karar tabanlı - deterministic" ve "olasılık tabanlı - probabilistic" yaklaşımlar karşılaştırılarak yöntemlerin performanslarının, pratik uygulama parametreleri ile ortamın doğasına büyük ölçüde bağımlı olduğu belirtilmiştir [17]. Aynı çalışmada karar tabanlı yöntemlerden KNN metodunun kısa mesafelerde daha doğru sonuç verdiği ve RSSI değeri nispeten değişmeyen ortamlarda $\mathrm{K}=1$ için $\mathrm{KNN}$ metodunun hesaplama maliyeti açısından uygun olduğu da ifade edilmiştir. On-line (eş zamanlı) fazla ilgili diğer bir çalışmada iç mekandaki konum belirleme için değişik fingerprint teknikleri sunulmuştur [22]. Bunlardan ilki "Multivariate Gaussian Model" kullanan istatiksel 
tabanlı bir yaklaşımdır. Bu yaklaşımda alınan sinyal ile RSSI haritalama veritabanındaki değer, "Kullback-Leibler Divergence, KLD" yöntemi ile kıyaslanmıştır. On-line fazı ile ilgili bir diğer çalışmada; fingerprint tekniğindeki doğruluk performansını daha da yükseltmek için bulanık mantıkla desteklenen bir KNN tekniği önerilmiştir [21]. Başka bir çalışmada da fingerprint tabanlı konum bulma sistemlerinde, kapalı alanlardaki RSSI ölçümünde kapılar ve duvarların bozucu etkisinin göreceli olarak üstesinden gelmek için ölçme, kalibrasyon ve lokasyon kestirimi fazlarından oluşan cihaz bağımsız bir yöntem önerilmiştir [9]. Bu yöntemin kalibrasyon fazında, bozucu büyüklüklerin etkisini belirlemek için RSSI değerleri normalize edilir ve benzer fiziksel mekanlardaki RSSI değerlerinin kümeler halinde oluşturulması sağlanır. Konum kestirimi fazında ise, sonuçları optimize etmek için veri madenciliği tekniği kullanılmıştır.

$\mathrm{Bu}$ makalede ise, kapalı alanlarda RSSI temelli fingerprint yöntemiyle konum tespiti sürecinde, radyo haritalama ve konum kestirimi fazları için yeni yaklaşımlar getirilmiştir. Bunlardan ilki, kullanılacak radyo haritasının genel yapısını bozmadan, K-means metodu yardımıyla her bir çapa düğüme ait RSSI verilerinin kendi örnek vektör uzaylarından ayrıştırılarak küçültülmesidir. Böylece kapalı alandaki dağılımı en uygun şekilde ifade edebilen küçük kapasiteli radyo haritası elde edilecektir. İkinci yaklaşım ise elde edilen radyo haritası ile etkileşen dinamik bir konum tespiti işlemi için, KNN metodu yerine kullanılabilecek, yeni geliştirilen karar tabanlı bir yöntemdir. $\mathrm{Bu}$ yöntem için kapalı çalışma alanı kalibrasyon verilerine göre mantıksal alt alanlara bölünür ve radyo haritasından okunan veriler bu alt alanlar içerisinde belirli bir sınırlamaya tabi kalmadan analiz edilir. $\mathrm{Bu}$ yaklaşımlardan amaç, fingerprint yöntemi için az sayıda sabit sensör düğüm kullanımı, daha küçük boyutlu RSSI haritası, daha hızlı konum tespiti ve konum tespiti doğruluk performansının artırılmasıdır. Makalenin ilerleyen bölümlerinde, önerilen sistemin tanıtımı, RSSI ölçme ve harita oluşturma, alt bölgeleme süreci, on-line faz için önerilen yöntem, deneysel çalışmalar, sonuçların karşılaştırılması ve değerlendirmeler açıklanacaktır.

\section{GELISSTIRILEN SISTEMIN TANITIMI} (THE DESCRIPTION OF THE PROPOSED SYSTEM)

$\mathrm{Bu}$ çalışmada önerilen fingerpint konum bulma sistemi için deneysel çalışmalar, 6 x 11 m'lik kapalı bir laboratuar ortamında yapılmıştır. Önerilen sistemin prensip şeması ve alanın krokisi Şekill'de verilmiştir. Şekill.b'de görüldüğü gibi çalışma alanının her bir köşesinde bir çapa düğüm (Ç1, Ç2, Ç3, Ç4) vardır. Mobil düğüm (MD) ise bu bölge içerisinde herhangi bir yerde bulunabilmektedir. Geliştirilen sistemin, "RSSI radyo haritalama fazı" için gerekli olan kalibrasyon verileri, kapalı alandaki RSSI ölçümlerinden elde edilmiştir. K-Means kümeleme metodu kullanılarak bu kalibrasyon verilerinin oluşturduğu radyo haritasının boyutları küçültülmüştür. Ayrıca radyo haritalama fazının diğer bir adımı olarak önerilen "mantıksal alt bölgeleme" işleminde de kalibrasyon verileri kullanılmaktadır. Sistemin "konum kestirimi" fazında ise, mobil düğümden okunan RSSI değerleri ile, indirgenmiş veritabanı ve alt bölgeleme bilgileri beraber değerlendirilerek mobil düğümün bulunduğu hücrenin koordinatlarına göre konum tespiti işlemi gerçekleştirilmiştir.

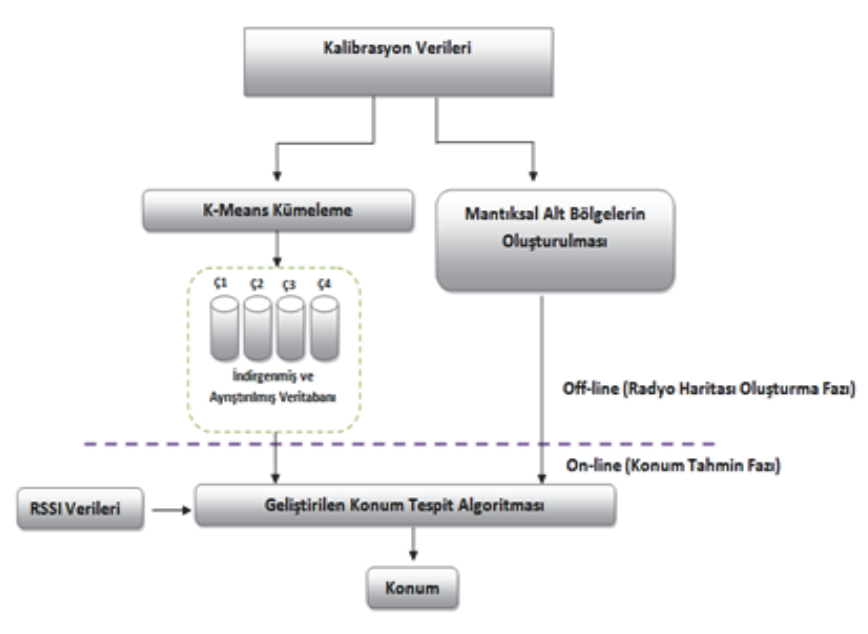

a)

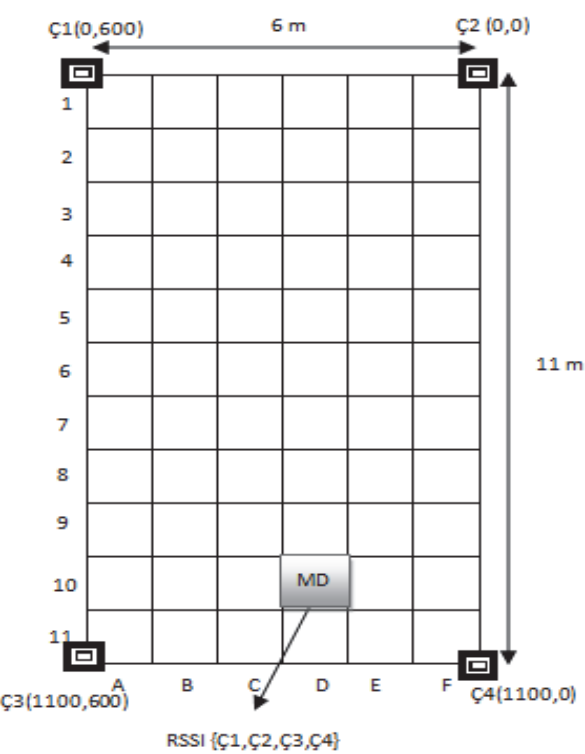

b)

Şekil 1. Kapalı alanın hücresel gösterimi ve önerilen tekniğge ait akış şeması (The follow diagram of the system and the cellular form of the closed area) 
Şekill.a'da prensip şeması verilen bu sitemin gerçekleştirme detayları alt bölümlerde açıklanacaktır. Önerilen sistemde kullanılan tüm düğümler MEMSIC TelosB tipindedir. $\mathrm{Bu}$ dügümlerden biri "Toplayıcı düğüm - Basestation” olarak kullanılmıştır. Toplayıcı düğümün bağlı olduğu bilgisayarda UBUNTU işletim sistemi kurulu olup, TinyOS 2.1.0 gömülü işletim sistemi ve düğüm kodlarının deneneceği TOSSIM emülatörü bulunmaktadır. Düğüm kodları nesC dilinde yazılmış ve TinyOS ortamında derlenmiştir. Alınan verilerin analiz edileceği uygulama yazılımı JAVA ortamında geliştirilmiştir. Deneyler esnasında okunan RSSI verilerinin çapa düğümlerin voltaj seviyelerinden etkilenmemesi için, pil yerine sabit güç kaynakları kullanılmıştır. Deneyler süresince kapalı ortamının sıcaklığı 22-23 ${ }^{0} \mathrm{C}$ olarak ölçülmüştür.

\subsection{Radyo Haritasının Olușturulması (Construction of the Radio MAP)}

Sistemin RSSI haritasının oluşturulması için ortam Şekil 1.b'de gösterildiği gibi merkez koordinatları, Ç2 $(0,0)$ düğümüne göre göreceli olarak bilinen 66 adet 1x1 m'lik sanal hücrelere ayrılmıştır. Radyo haritalama fazında, yöntemin hassasiyetini artırmak amacıyla her bir sanal hücre içerisinde; sol üst, sol alt, sağ üst, sağ alt ve merkez olmak üzere beş farklı noktada her bir çapa düğüme ait örnek RSSI değerleri ölçülmüştür. Ölçülen RSSI değerlerinin tutarlılığını görmek maksadı ile bu ölçümlerin dişında, kapalı alanın her bir köşesinden ayrıca 30, 45, 60 ve 90 derecelik doğrusal ölçmeler yapılmıştır. Böylece 66 $\mathrm{m}^{2}$ 'lik bu kapalı alanda, noktasal ve doğrusal olarak toplam 1440 adet RSSI ölçümü yapılarak, koordinatları bilinen noktalar için RSSI imzası (parmak izi - fingerprint) elde edilmiştir. Genel olarak elde edilen RSSI verileri radyo haritasına Denklem 1 'de gösterildiği gibi vektörel formda kaydedilir. Burada $C_{i, j}$ radyo haritasındaki (i,j)'nci hücreye ait bilgi gösterim formatını, $\mathrm{S}_{\mathrm{ij}}$ sabit düğümlere ait RSSI verilerini tutan vektörü, " $\beta$ " ise istenilen opsiyonel verileri (yön bilgisi gibi) temsil etmektedir.

$C_{i, j}=\left(S_{i, j}, \beta\right)$

Bazı hücrelere ait örnek okumalar ve bunların yerleşimleri Şekil 2'de gösterilmiştir. Denklem 1'in özelleştirilmiş halini ifade eden Denklem 2, herhangi $i, j$ 'inci hücredeki mobil düğümün dört adet sabit düğümden alınan RSSI değerlerini ifade eden vektördür. Burada " $z$ " örnek numarasını temsil etmekte, $C_{1 z}, C_{2 z}, C_{3 z}, C_{4 z}$ ise sırasıyla dört sabit düğümden alınan $z$. örnek RSSI değerlerini göstermektedir. Yapılan bu çalışmada alınan RSSI örnekleri -38 ile $-85 \mathrm{dBm}$ arasında değişmektedir. $\mathrm{Bu}$ iki değer aralığındaki değişim RSSI'ın doğasından kaynaklanan etkenlerden dolayı doğrusal değildir. Uygulamada $-83 \mathrm{dBm}$ ve sonraki veri paketleri kötü paket (Bad Packet) olarak okunduğu için bu değerlerin üstü $-83 \mathrm{dBm}$ olarak kabul edilmiştir.

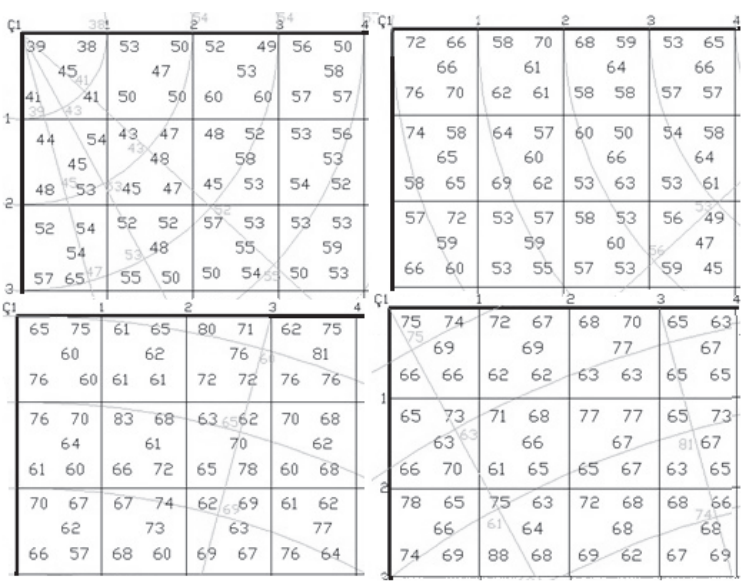

Şekil 2. Bazı hücrelere ait örnek noktasal ve doğrusal okuma sonuçları (Point and linear records for some cells)

$C_{i j, z}=\left\{C_{1 z}, \quad C_{2 z}, \quad C_{3 z}, \quad C_{4 z}\right\}$

$C_{c 2,1}=\{48,60,63,77\}$

$C_{c 2,2}=\{52,50,62,77\}$

$C_{c 2,3}=\{58,66,70,67\}$

$C_{c 2,4}=\{45,53,65,65\}$

$C_{c 2,5}=\{53,63,78,67\}$

İşlem kolaylığı açısından, RSSI verilerinin pozitif değerleri kullanılmıştır. Denklem 2.b'de $1 \mathrm{~m}^{2}$ 'lik C2 hücresinde $\mathrm{z}=5$ için çapa düğümlerden alınan RSSI değerleri verilmiştir. Buradan görüldüğü gibi, bir hücrede bir çapa düğümden alınan RSSI verileri farklılıklar gösterebilmektedir. Bu farklılığa sebep olabilen etkenler pratik uygulamalarda göz ardı edilemeyeceğinden, hücrenin RSSI karakteristiği radyo haritasına uygun bir şekilde işlenmelidir. Ayrıca elde edilen radyo haritasında kestirim aşamasını zorlaştıracak bir değer dağılımı da söz konusudur. Örneğin Şekil 3'ten görüleceği gibi kapalı alan üzerinde 57 ile $67 \mathrm{dBm}$ arası RSSI değerlerinin okunduğu hücre sayısı oldukça fazla olup bu hücreler konum olarak da birbirlerine yakın değildirler. $\mathrm{Bu}$ durumun konum tespiti fazında kararsızlıklara ve yanlış değerlendirmelere sebep olabileceği açıktır. Öte yandan radyo haritasının boyutunun küçük olması bütün tekniklerde arzu edilen bir durumdur.

$\mathrm{Bu}$ makaledeki yaklaşımın amaçlarından birisi yukarıda açıklanan problemleri çözmeye yöneliktir. İlk olarak çözülmesi gereken problem, ölçülen RSSI değerlerinin nispeten daha kararlı hale getirilmesidir. Bunun için kalibrasyon verilerini belirli merkezlere göre kümeleyerek, hem radyo haritasının küçülmesi hem de kapalı alanın daha genel haritalanmasını belirleyen RSSI tablolarının oluşturulması sağlanmıștır. Ayrıca diğer radyo haritalama kümelemelerinden farklı olarak, bu teknikte her bir çapa düğüme ait kalibrasyon verisi kendi örnek uzayından ayrılmakta ve tek olarak tablolanmaktadır. $\mathrm{Bu}$ tip tablolama, geliştirilen konum tespit algoritması için daha dinamik bir özellik sağlamaktadır. 

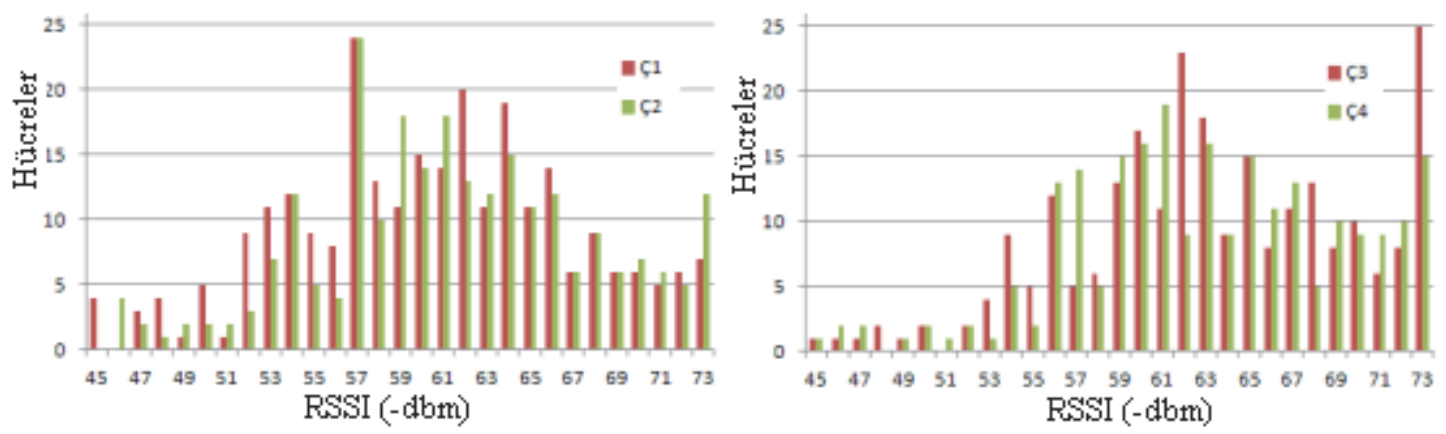

Şekil 3. Kalibrasyon verilerinden oluşturulan RSSI-Hücre histogramları (The histograms of RSSI-Cell for the calibration data)

Tablolamada her çapa düğümden elde edilen benzer RSSI değerli hücrelerin kümelenmesi için, makine öğrenmesi tekniklerinden biri olan "K-Means" metodu kullanılmıştır $[10,18,23]$. K-means metodu için giriş verileri, her bir çapa düğümden ölçülen benzer RSSI değerlerine sahip hücre koordinatlarının oluşturduğu $\mathrm{H}=\{\mathrm{h} 1, \mathrm{~h} 2, . ., \mathrm{hn}\}$ aday kalibrasyon verileridir. $\mathrm{C}=\left\{\mathrm{c} 1, \mathrm{c} 2, \ldots \mathrm{c}_{\mathrm{K}}\right\}$ ise, herhangi bir çapa düğüm için aynı RSSI değerlerinin okunduğu farklı hücrelerin oluşturacağı kümelerin merkezleri için hesaplanmış koordinat değerleri verileridir. K-means algoritmasının 1. adımı, küme merkezlerinin gelişigüzel seçimidir. Bu çalışmada, benzer değerli hücreler için oluşturulacak küme merkezi sayısı K, hücrelerin birbirlerine olan yakınlığı, sayıları ve coğrafi konumları göz önüne alınarak 1 veya daha farklı seçilmiştir. Bu seçim oldukça kritik olup, elde edilen kalibrasyon verileri dikkate alınmış, ayrıca algoritma için seçilen küme merkezlerinin başlangıç değerlerinin seçimi de kalibrasyon verilerindeki dağılımı da göz önünde bulundurulmuştur. Algoritmanın 2. adımı, ilgili hücrelerin seçilen küme merkezlerine mesafelerinin yeniden hesaplanmasıdır. K-Means metodunun genel ifadesi Denklem 3'tedir.

$\arg \min \sum_{t=1}^{K} \sum_{j=1}^{n}\left\|h_{j}-c_{t}\right\|^{2}$

Burada amaç, her bir üyenin, tüm küme merkezlerine olan en kisa mesafesinin elde edilmesidir. $\left\|h_{j}-c_{t}\right\|$, $\mathrm{h}_{\mathrm{j}}$ ile $\mathrm{c}_{\mathrm{t}}$ arasındaki oklit mesafesidir. $K$ küme merkezlerinin sayısını ifade ederken $n$ toplam aday hücre sayısını göstermektedir.

$$
\begin{aligned}
& c(x)=\left(\frac{1}{C p}\right) \sum_{i=1}^{C p} h_{i}(x) \\
& c(y)=\left(\frac{1}{C p}\right) \sum_{i=1}^{C p} h_{i}(y)
\end{aligned}
$$

Algoritmanın 3.aşaması küme merkezine en yakın hücrelerin ilgili kümelere aktarılmasıdır. Denklem 4 ve 5'e göre küme merkezlerinin yeniden hesaplanması işlemi ise K-means algoritmasının 4. adımını oluşturur. Burada $\mathrm{Cp}$ elde edilen yeni küme içerisindeki aday elemanların sayısını, $h_{i}(x)$ ve $h_{i}(y)$ ise bu aday hücrelerin koordinat bilgilerini göstermektedir. Beşinci adımda ise bu yeni küme merkezine göre, hücrelerin mesafeleri yeniden hesap edilerek değişim miktarı belirlenir. Değişim yok ise kümeleme tamamlanmıştır. K-Means algoritmasını sağlayan yazılımın kaba kodu Şekil 4'te verilmiştir. Elde edilen sonuçlara örnek olması amaciyla, okunan $52 \mathrm{dBm}$ 'lik RSSI değerleri için yapılan bir kümeleme ( $\mathrm{K}=2$ için) Şekil 5'te verilmiştir. Şekil 5'ten görüldüğü gibi aynı RSSI değerine sahip birçok hücre farklı merkezlere sahip değişik kümelerin elemanları olabilmektedir. $\mathrm{Bu}$ durum, bir sonraki bölümde açıklanacak mantıksal alt bölmeleme işleminden sonra konum tespiti analizinin daha doğru ve daha kısa bir sürede yapılması için önemlidir. Kümeleme sonucunda bir hücre farklı RSSI değerlerine sahip olabilmektedir. $\mathrm{Bu}$ nedenle yapilan indirgeme işleminin sonuçlarının, ampirik bir yaklaşımla tekrar incelenmesinde fayda vardır. Yapılan çalışmada her değer için belirli bir küme sayısı belirlenerek gerekli indirgeme ve ampirik analiz işlemleri tamamlandıktan sonra kapalı alan içindeki RSSI-hücre histogramı ile Çapa1 için elde edilen örnek bir karakteristik yap1 Şekil 6'da gösterilmiştir. Şekil 6'dan görüleceği üzere kapalı alana ait radyo haritasının boyutu oldukça küçülmüştür. Dört çapa düğüm için bu şekilde oluşturulan dağıtık değer sayısı 213 olarak gerçekleşmiştir.

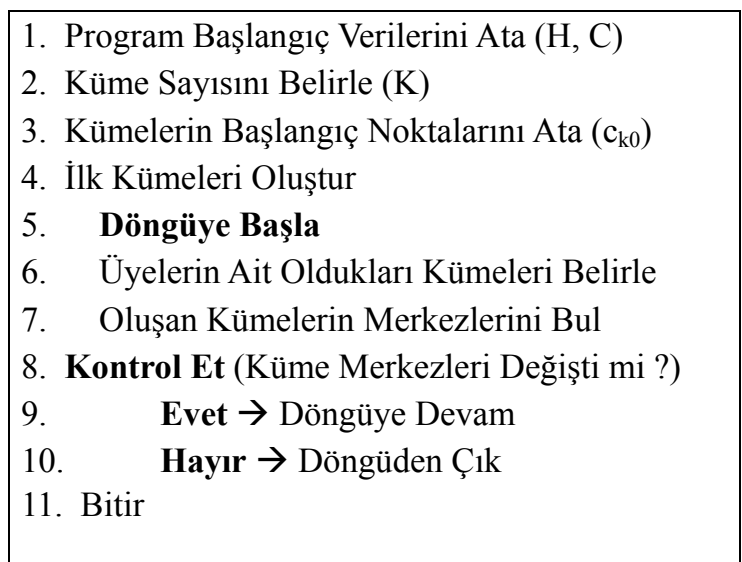

Şekil 4. K-Means Algoritması kod şablonu (The pseudocode of the K-Means Method) 


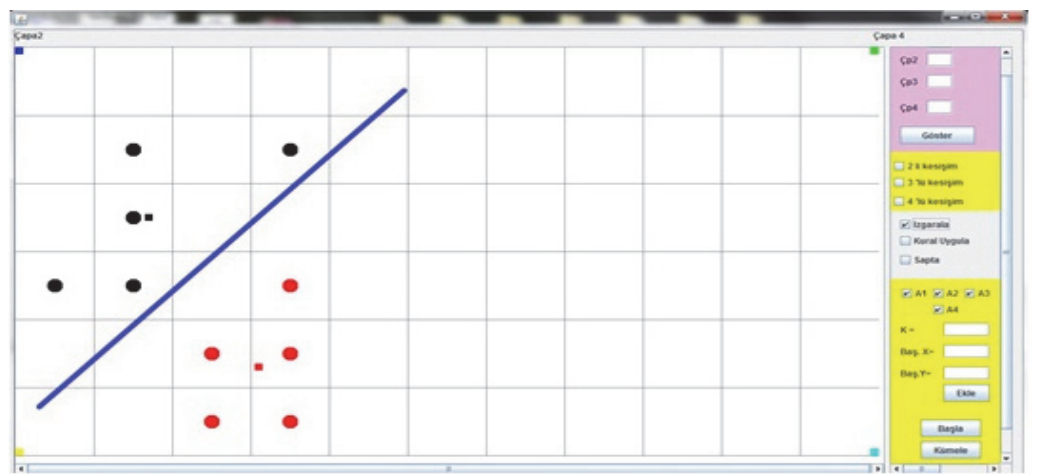

Şekil 5. $52 \mathrm{dBm}$ ve $\mathrm{K}=2$ için örnek kümeleme (A sample clustering for $\mathrm{K}=2$ and $52 \mathrm{dBm}$ )
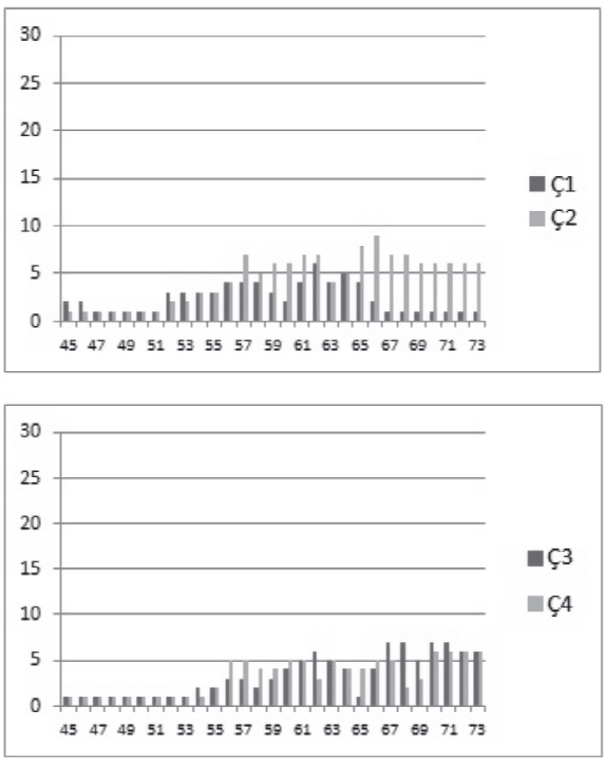

a)

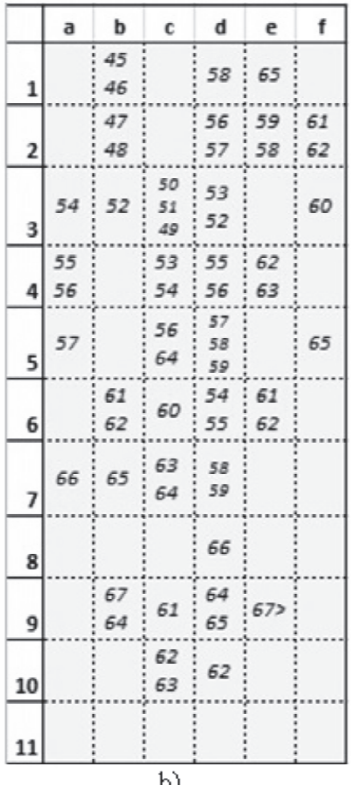

Şekil 6. Her çapa için yeni RSSI-hücre histogramı ve Çapa1 için örnek radyo haritası (The new histograms of RSSI-Cells for each anchor and the sample radio map for Anchor1)

2.2 Mantıksal Alt Bölge Oluşumu (Formation of The Logical Subfields)

Şekil 6.b'deki indirgenmiş radyo haritasından görüldüğü gibi kapalı alanın farklı bölgeleri için aynı RSSI ölçüm değerleri mevcuttur. Diğer çapa düğümler için de geçerli olan bu durumdan dolayı online fazda elde edilen sonucun hata miktarının artması söz konusu olabilmektedir. Bunun önüne geçebilmek, konum tespitini kolaylaştırmak ve daha kararlı hale getirmek için bu çalışmada “Alt Bölge Analizi” isimli bir ara işlem gerçekleştirilmiştir. Kapalı alandaki dağıtık RSSI yapısının filtrelenmesini amaçlayan bu işlem, kalibrasyon verilerindeki dört çapa düğümden alınmış deneysel RSSI verilerinin değerlendirilmesinden oluşur. Buna göre bir hücrelik tolerans paylarının eklenmesi ile oluşturulan 6 adet mantıksal alt bölge Tablo 1'deki kurallara göre seçilmiştir. Burada $\mathrm{T}$, tanımlı bir kalibrasyon veri kümesidir. Kapalı alanda bu kurallara göre elde edilmiş olan alt alanlar Şekil 7'de gösterilmiştir. Mantıksal alt bölgelemeni $\mathrm{n}$ getireceği önemli bir avantaj, bölgelerin kendi içerisinde bağımsız olarak analiz edilebilir olmasıdır. Böylelikle konum tahmin fazında daha doğru bir kestirim ve daha az hesap zamanı sağlanmış olacaktır.

Tablo 1. Alt bölge seçim Kriterleri (The criterions of the logical subfields)

\begin{tabular}{|c|c|}
\hline$(C ̧ 1<48) \cap\{C ̧ 2, C ̧ 3, C ̧ 4\} \in \mathrm{T}$ & 1.Bölge \\
\hline$(C ̧ 2<46) \cap\{C ̧ 1, C ̧ 3, C ̧ 4\} \in \mathrm{T}$ & 2.Bölge \\
\hline$(47<C ̧ 1<50) \cap(46<C \zeta 2<52) \cap\{C ̧ 3, C ̧ 4\} \in \mathrm{T}$ & 3.Bölge \\
\hline$(C ̧ 3<58) \cap(C ̧ 4<60) \cap\{C ̧ 1, C ̧ 2\} \in \mathrm{C}$ & 4.Bölge \\
\hline$(C ̧ 4<51) \cap\{C ̧ 1, C ̧ 2, C ̧ 3\} \in T$ & 5.bölge \\
\hline$(C ̧ 1>53) \cap(C ̧ 2>54) \cap(C ̧ 3>57$ & \\
\hline
\end{tabular}

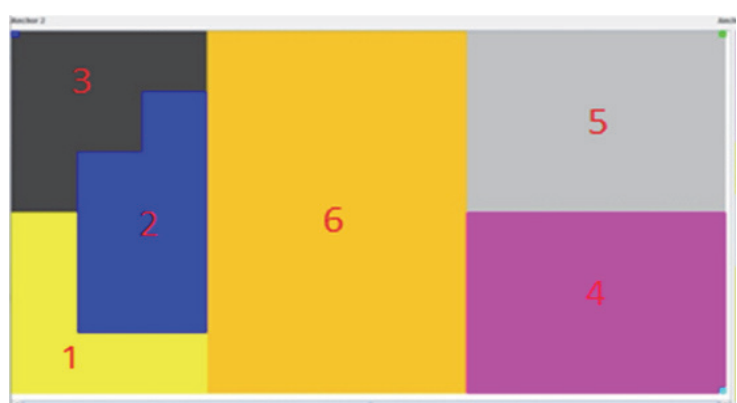

Şekil 7. Mantıksal alt alanlar (The logical subfields) 
Tablo 2. Örnek analiz yapısı (An analysis format for a sample RSSI data)

\begin{tabular}{|c|c|c|c|c|c|c|c|}
\hline $\begin{array}{c}\text { On-line } \\
\text { RSSI }\end{array}$ & $\begin{array}{c}\text { Gerçek } \\
\text { Kord. }(\mathrm{cm})\end{array}$ & $\begin{array}{c}\text { Bul. gerçek hüc. } \\
\text { Kord.(cm) }\end{array}$ & Elde edilen hücreler & $\begin{array}{c}\text { Mant. } \\
\text { alt } \\
\text { alan }\end{array}$ & $\begin{array}{c}\text { Filtrenmiş } \\
\text { Hücreler }\end{array}$ & $\begin{array}{c}\text { Hesapl. } \\
\text { Kord.(cm) }\end{array}$ & $\begin{array}{c}\text { Hata } \\
(\mathrm{cm})\end{array}$ \\
\hline $61 / 65 / 65 / 62$ & $(480,190)$ & e5 (450,150) & $\begin{array}{l}\text { c1,a2,f2,a3,c5,b6,c6, } \\
\text { f6,e7,d7,b8,c9,b10,e10 }\end{array}$ & 6 & $\begin{array}{l}\text { c5,b6,c6, } \\
\text { f6,e7,d7 }\end{array}$ & $(578,250)$ & 114,90 \\
\hline
\end{tabular}

\subsection{Konum Tespiti (Location Estimation)}

Mobil düğümün çapa düğümlerden on-line olarak okuduğu RSSI değerleri ile mobil düğümün konum tespit işlemi; radyo haritasından bu değerlerle ilgili hücrelerin getirilmesi, on-line RSSI verilerine göre mantıksal alt bölgenin belirlenmesi, buna göre hücrelerin filtrelenmesi ve elde edilen hücrelerin merkez koordinatlarının aritmetiksel ortalamasının alınıp koordinat belirlenmesi șeklindedir. Tablo 2'de bu yönteme ait bir analiz örneği gösterilmektedir.

\section{UYGULAMA VE DENEYLER (IMPLEMENTATION AND TESTING)}

Bu çalışmada geliştirilen uygulama yazılımı; önerilen tekniğin konum bulma için kullanılan klasik KNN yöntem sonuçları ile karşılaştırılabilmesi için, giriş RSSI değerlerini, her iki tekniğe göre hesaplamaları, K-Means kümeleme hesaplamalarını ve gerçek koordinat değerlerini gösterebilecek şekilde oluşturulmuştur. Şekil 8'de arayüzü görülen yazılımın çalışması şu şekildedir; mobil düğümün alandan online olarak okuduğu RSSI değerlerinin toplayıı düğüm vasıtasıyla girdi olarak alınmasıyla (veya el ile daha sonra RSSI girişiyle), Düzenlemeler menüsünden seçilen önerilen yöntem/yöntemlere göre hesap edilmektedir. Arayüz üzerinde bulunan $1100 \mathrm{x}$ 600 piksellik beyaz alan 11x6 m'lik kapalı alanı temsil etmektedir. Çalışma alanında her bir çapa düğüm okumaları, alt bölge analizleri, gerçek koordinat bilgileri, hesaplanan pozisyon bilgileri ayrı ayrı görülebilmektedir. Karşılaştırma için kullanılan
KNN konum tespiti metodundaki radyo haritası, her hücre için her bir çapa düğüme ait RSSI değerlerinin ortalamaları alınarak oluşturulmuştur. $\mathrm{Bu}$ ortalama değerlere göre KNN için elde edilen radyo haritasındaki dağıtık değer sayısı 264'tür. KNN metodunda mesafe hesaplaması için Denklem.6'daki gösterilen p-norm kullanılabilir [14]. Bu çalışma için $\mathrm{p}=2$ seçilerek "Oklit -norm" tercih edilmiştir.

$$
\|d\|_{p}=\left(\sum_{i=1}^{\partial}\left|d_{i}\right|^{p}\right)^{1 / p}\|d\|\left(d \in R^{\partial}\right)
$$

Her iki yöntem için yapılan deney sonuçları Denklem. 7'deki "ortalama hata" kriterine göre değerlendirilmiştir. Burada " $T$ " test sayısını, " $\mathrm{r}_{\mathrm{x}}$ ", " $\mathrm{r}_{\mathrm{y}}$ " gerçek koordinatları ve " $f_{\mathrm{x}}$ ", " $f_{\mathrm{y}}$ " hesaplanan koordinatları ifade etmektedir.

$$
M E r=\frac{1}{T} \sum_{i=1}^{T} \sqrt{\left(r_{x i}-f_{x i}\right)^{2}+\left(r_{y i}-f_{y i}\right)^{2}}
$$

Çalışmanın gerçekleştirildiği laboratuar ortamından bir görüntü Şekil 9'da verilmiştir. Yapılan 32 adet deneyin sonuçları Şekil 10,11 ve Tablo3'te verilmiştir. Şekil 10'da görüldüğü gibi önerilen teknik, 1-NN, 2$\mathrm{NN}$ ve 3-NN tekniklerine göre mobil dügümün yerini daha az hata ile tespit etmektedir. Ancak KNN metodu, çapa düğümlere çok yakın bölgelerde önerilen tekniğe göre biraz daha iyi sonuç vermektedir.

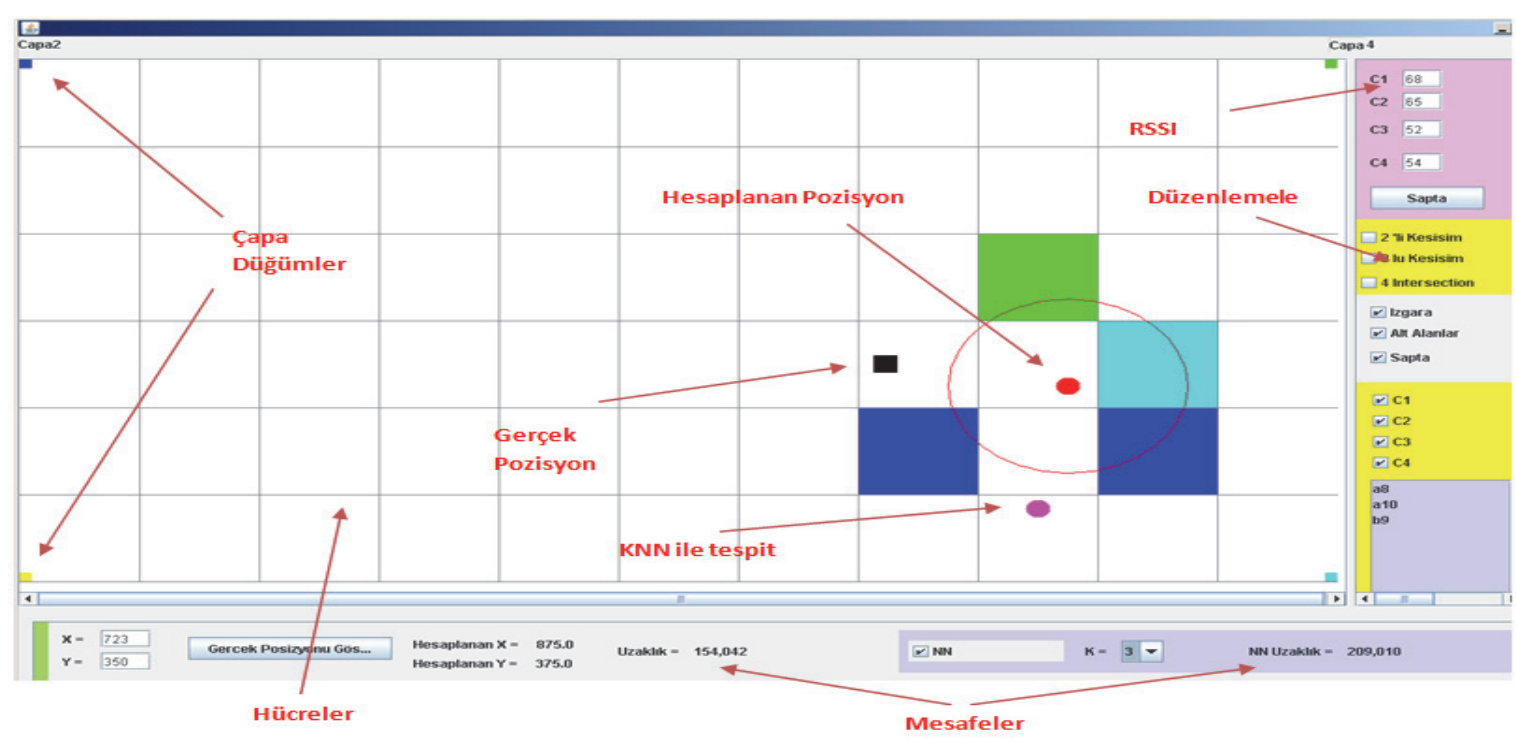

Şekil 8. Uygulama yazılımı arayüzü (The interface of the application program) 
Şekil 11'de ise mobil düğümün kapalı alandaki gerçek koordinatlarına ( $\mathrm{x}, \mathrm{y}$ düzleminde) göre; önerilen yöntem ve KNN yöntemlerinden alınan yaklaşım mesafeleri verilmiştir. Buradan da önerilen yöntemin özellikle orta alanlarda daha doğru sonuçlar verdiği görülmüştür.

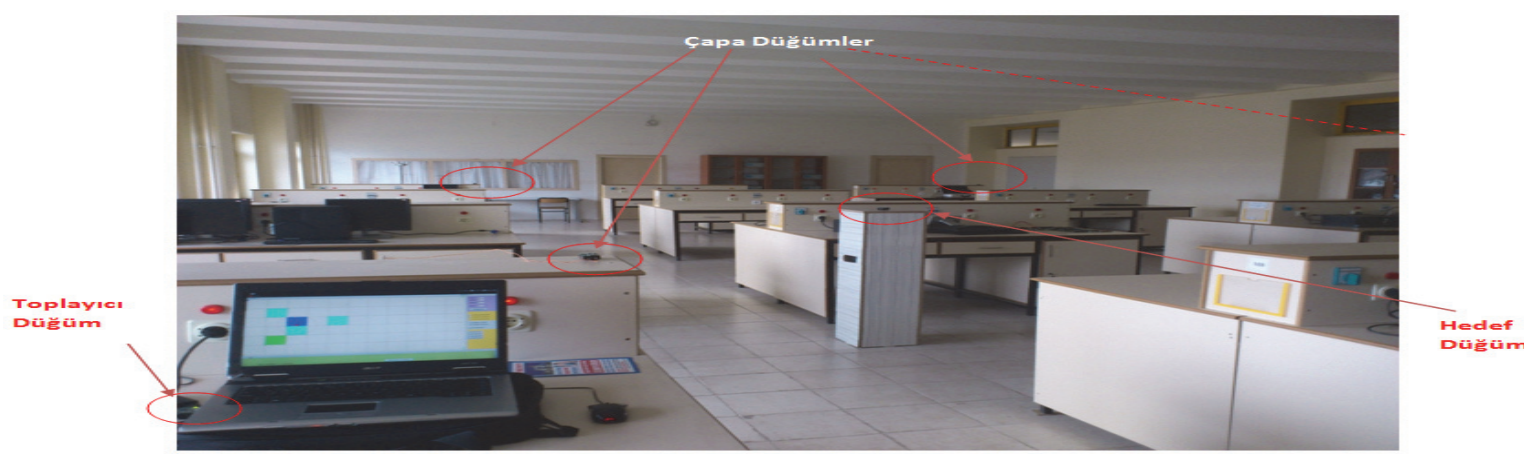

Şekil 9. Çalışma alanından bir görüntü (A view of the testing area)
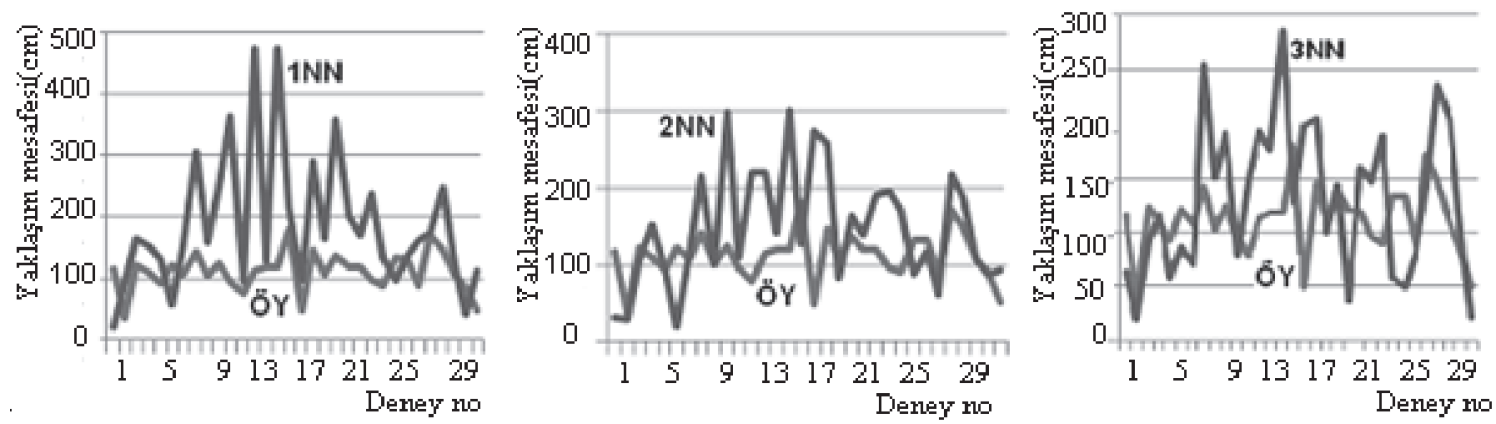

Şekil 10. Önerilen yöntem (ÖY) ile 1-NN, 2-NN, 3-NN yönteminin hata miktarlar (The error distance for the proposed technique, 1-NN, 2-NN, 3-NN)

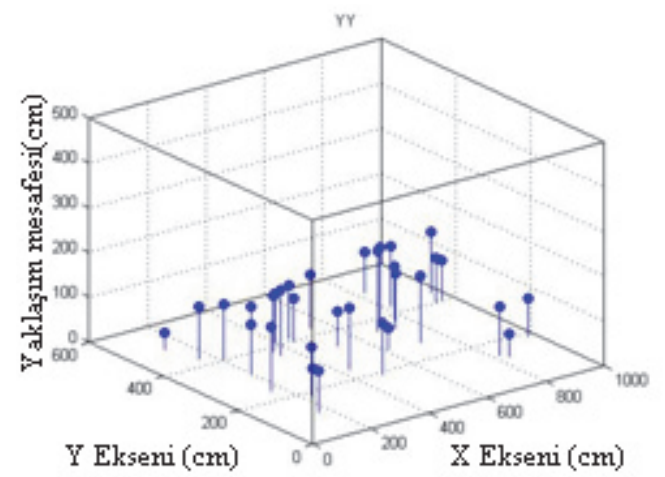

a) Önerilen Yöntem

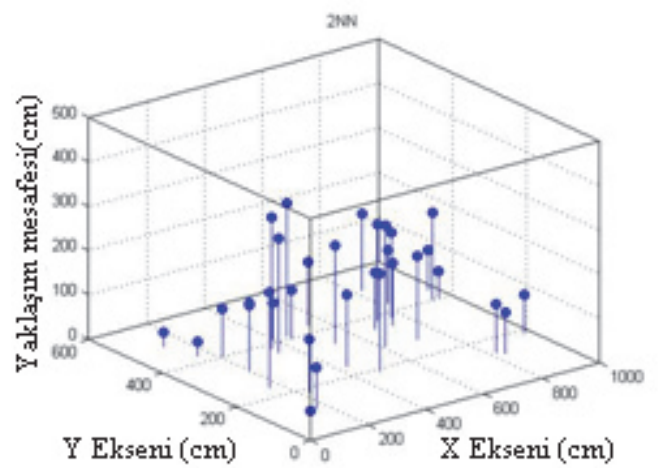

c) $2 \mathrm{NH}$

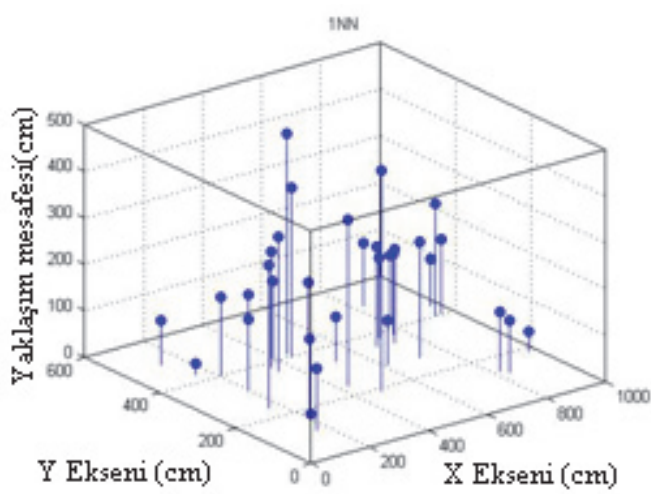

b) $1 \mathrm{NN}$

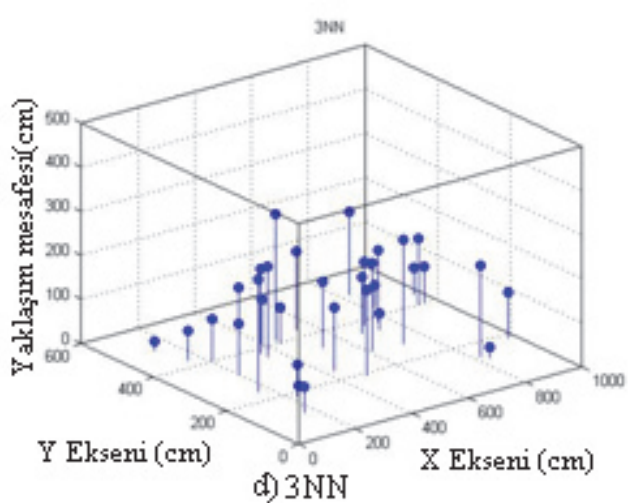

Şekil 11. Önerilen yöntem ve 1-NN, 2-NN, 3-NN yönteminin ölçüm yerlerindeki hata dağılımları (The error distribution of the all methods for the real points) 
Tablo 3. Deney Sonuçları (The results of the experiments)

\begin{tabular}{|c|c|c|c|c|c|c|c|}
\hline \multirow{2}{*}{$\begin{array}{c}\text { Deney } \\
\text { No }\end{array}$} & \multirow{2}{*}{$\begin{array}{c}\text { RSSI } \\
\text { seti }\end{array}$} & \multicolumn{2}{|c|}{ Gerçek konum (cm) } & \multicolumn{4}{|c|}{ Gerçek konuma yaklaşım mesafesi $(\mathrm{cm})$} \\
\hline & & $\mathbf{X}$ & $\mathbf{Y}$ & Önerilen & $1 \mathbf{N N}$ & $2 \mathbf{N N}$ & 3NN \\
\hline 1 & $48 / 60 / 73 / 68$ & 160 & 430 & 117,24 & 22,361 & 31,623 & 64,382 \\
\hline 2 & $42 / 73 / 71 / 73$ & 130 & 500 & 36,00 & 94,34 & 30 & 21,26 \\
\hline 3 & $52 / 57 / 67 / 68$ & 210 & 405 & 123,00 & 166,20 & 105,47 & 93,00 \\
\hline 4 & $54 / 53 / 66 / 64$ & 200 & 322 & 110,65 & 152,59 & 151,60 & 116,16 \\
\hline 5 & $70 / 42 / 67 / 66$ & 165 & 115 & 91,92 & 132,09 & 91,92 & 58,52 \\
\hline 6 & $54 / 37 / 73 / 71$ & 100 & 80 & 122,00 & 58,31 & 20,00 & 86,00 \\
\hline 7 & $66 / 47 / 67 / 64$ & 230 & 185 & 106,88 & 156,92 & 116,72 & 70,40 \\
\hline 8 & $57 / 53 / 61 / 69$ & 165 & 240 & 142,35 & 305,49 & 215,23 & 254,65 \\
\hline 9 & $51 / 59 / 73 / 73$ & 300 & 400 & 103,08 & 158,11 & 100,00 & 150,96 \\
\hline 10 & $56 / 53 / 73 / 75$ & 350 & 380 & 124,47 & 250,80 & 297,32 & 192,08 \\
\hline 11 & $56 / 60 / 62 / 59$ & 445 & 400 & 95,77 & 362,66 & 109,65 & 79,64 \\
\hline 12 & $54 / 60 / 58 / 66$ & 520 & 340 & 77,46 & 94,86 & 220,22 & 148,38 \\
\hline 13 & $61 / 65 / 65 / 62$ & 480 & 190 & 11,00 & 473,81 & 220,22 & 193,77 \\
\hline 14 & $56 / 55 / 58 / 72$ & 545 & 435 & 118,60 & 127,48 & 142,30 & 175,50 \\
\hline 15 & $60 / 66 / 58 / 57$ & 450 & 415 & 118,90 & 472,46 & 299,50 & 285,50 \\
\hline 16 & $63 / 59 / 58 / 61$ & 670 & 350 & 180,80 & 215,40 & 128,06 & 128,00 \\
\hline 17 & $59 / 62 / 59 / 70$ & 610 & 275 & 49,47 & 96,05 & 273,35 & 198,64 \\
\hline 18 & $55 / 57 / 58 / 64$ & 350 & 360 & 145,60 & 290,00 & 256,12 & 204,00 \\
\hline 19 & $56 / 57 / 64 / 70$ & 400 & 415 & 107,49 & 163,47 & 82,00 & 100,44 \\
\hline 20 & $58 / 65 / 60 / 69$ & 430 & 240 & 137,43 & 358,46 & 162,78 & 144,39 \\
\hline 21 & $70 / 58 / 56 / 57$ & 730 & 350 & 120,00 & 200,99 & 139,28 & 35,84 \\
\hline 22 & $67 / 60 / 54 / 58$ & 765 & 380 & 119,57 & 170,66 & 190,06 & 160,37 \\
\hline 23 & $62 / 65 / 54 / 56$ & 940 & 405 & 95,96 & 239,00 & 195,25 & 146,49 \\
\hline 24 & $67 / 70 / 56 / 72$ & 830 & 510 & 89,05 & 134,16 & 170,29 & 187,94 \\
\hline 25 & $64 / 66 / 57 / 60$ & 975 & 445 & 132,85 & 98,23 & 87,46 & 59,21 \\
\hline 26 & $62 / 63 / 50 / 57$ & 825 & 435 & 132,38 & 137,30 & 117,68 & 48,83 \\
\hline 27 & $65 / 59 / 52 / 67$ & 960 & 405 & 87,32 & 160,62 & 60,20 & 81,32 \\
\hline 28 & $62 / 61 / 50 / 57$ & 715 & 380 & 170,88 & 173,56 & 217,08 & 144,25 \\
\hline 29 & $70 / 71 / 55 / 56$ & 715 & 270 & 147,73 & 248,24 & 187,41 & 235,35 \\
\hline 30 & $65 / 61 / 55 / 52$ & 825 & 145 & 107,93 & 125,10 & 107,93 & 205,19 \\
\hline 31 & $63 / 62 / 62 / 46$ & 975 & 185 & 85,00 & 43,01 & 88,60 & 102,31 \\
\hline \multirow[t]{2}{*}{32} & $62 / 67 / 54 / 49$ & 840 & 130 & 50,00 & 111,80 & 92,19 & 22,36 \\
\hline & & & MEr $=$ & 111,31 & 187,33 & 147,11 & 131,10 \\
\hline
\end{tabular}

Tablo 3'te ise 32 adet deneye ait mobil dügüumün ölçtüğü RSSI değerleri, gerçek koordinatlar, her iki yöntem için yaklaşım mesafeleri ve ortalama yaklaşım hatası (MEr) değerleri verilmiştir. $\mathrm{MEr}$ değerlerine göre de önerilen yöntemin KNN tekniğine göre daha az hatayla konum tespiti yaptığ görülmektedir. Ancak, çalışma alanının kenarlarına çok yakın noktalarda her iki tekniğin de çok başarılı olmadığı söylenebilir.

\section{SONUÇLAR VE TARTIŞMA (CONCLUSION AND DISCUSSION)}

Bu çalışmada RSSI temelli imza tabanlı konum bulma sürecinin iyileştirilmesine yönelik yeni geliştirme ve gerçekleştirmeler sunulmuştur. Bunlardan bir tanesinde daha küçük boyuta sahip, esnek ve çalışma alanını düzgün ifade edebilecek bir radyo haritası oluşturulmuştur. Bunun için, ölçümlerden elde edilen hücre RSSI değerlerinin, giriş değerleri olarak kullanıldığı, K-means algoritmasına göre her bir çapa düğüm için ayrı ayrı indirgenmiş veri uzayları oluşturulmuştur. $\mathrm{Bu}$ şekilde elde edilen haritalama, KNN yönteminde kullanılan haritalamaya göre $\% 20$ (213/264) oranında küçülmüştür. İkinci geliştirme ise ilgili alanı alt bölgelere indirgeyip, belirlenen alt alan içindeki dağılım şekline göre konum tespitini daha doğru yapabilecek bir tekniktir. Geliştirilen tekniğin KNN'den en büyük farkı; karar için KNN metodunda olduğu gibi sabit bir "K" değerine bağlı olmamasıdır. Saptanan alt bölgede işaretlenen hücrelerin sayısı bu teknikte tamamen dinamiktir ve indirgenmiş radyo haritasının oluşturulmasındaki ayrı örnek çapa uzaylarına bağlıdır.

Önerilen yöntemden elde edilen sonuçlar, mevcut test ortamına uygulanan ve literatürde karar tabanlı yaklaşım olarak bilinen KNN metodu temelli konum tespiti tekniğinden elde edilen sonuçlarla karşılaştırılmıştır. Bu bağlamda ortalama hata oranı (MEr) verilerine göre önerilen yöntemin, KNN temelli konum tespiti tekniğinden daha iyi sonuçlar verdiği gözlemlenmiştir. Ancak bu önerilen yöntem de 
çok yakın veya sınır çizgileri üzerindeki noktalarda istenilen sonucu verememiştir.

$\mathrm{Bu}$ çalışmada önerilen tekniğin, yumuşak hesaplama metotları ile nasıl geliştirilebileceği ve olasılık tabanlı konum tespit sistemlerine göre nasıl sonuç vereceği farklı çalışmalar için konu teşkil edebilir.

\section{KAYNAKLAR (REFERENCES)}

1. Pal, A., "Localization Algorithms in Wireless Sensor Networks: Current Approaches and Future Challenges",Network Protocols and Algorithms, Cilt 2, No 1, 45-74, 2010.

2. Farahani, S., "ZigBee Wireless Networks and Transceivers", Newness is An Imprint of Elsevier-Oxford, ISBN: 978-0-7506-8393-7, 2008.

3. Kulaib, A. R., Shubair, R. M., Al-Qutayri, M. A., ve Jason, W. P. N., "An Accurate Localization Technique for Wireless Sensor Networks Using MUSIC Algorithm”, Journal Of Communications, Cilt 7, No 4, 281-288, 2012.

4. Naik, G.A., Khedekar, M.P., Krishnamoorthy, M., ve Deshmukh. R.N., "Comparison of RSSI Techniques in Wireless Indoor Geolocation", NCCCS, Hindistan, 1-5, 21 Kasım 2012

5. Yildırım, G., ve Tatar, Y., "Enhancement Of The Empiric RSSI - Distance Relationship By Experimental Datum In Wireless Sensor Networks", IADIS International Conference Applied Computing 2012, Madrid, İspanya, 380384, 2012

6. Mitilineos, S. A., Kyriazanos, D. M., Segou, O. E., Goufas, J. N., ve Thomopoulos, S. C. A.,'Indoor Localisation With Wireless Sensor Networks" Progress In Electromagnetics Research, Cilt 109, 441-474, 2010.

7. Bahl, P., ve Padrnanabhan, V.N.,"RADAR: An InBuilding RF-BASED User Location and Tracking System," INFOCOM, Cilt 2,775-784, April,2000.

8. Narzullaev, A., Park ,Y., Yoo, K., ve Yu J., "A Fast and Accurate Calibration Algorithm For RealTime Locating Systems Based On The Received Signal Strength Indication", Int. J. Electronic Communitaion (AEÜ), Cilt 65, No 4, 305-311, 2011.

9. Mengual L., Marbán O., ve Eibe, S., “Clusteringbased location in wireless Networks", Expert Systems with Applications, Cilt 37, No 9, 6165 $6175,2010$.

10. Forero P.A., , Cano A., , Giannakis G.B., "Consensus-based k-means Algorithm for Distributed Learning using Wireless Sensor Networks", Workshop on Sensors, Signal and Information Process., 2008 .

11. Gómez, J.A., Medina, A., Dorronzoro, V., Rivera, O., ve Martín,S., "Fingerprint Indoor Position System Based on Bitcloud and Openmac", Journal of Networks, Cilt 8, No 1, 37- 44, 2013.

12. Hur, S., Choi, J., ve Park, Y., 'Fingerprint
Location Database Construction for Enhancing Accuracy of WiFi based Indoor Localization", ISA-IST2012, Şangay, Çin, 188-190, Nisan, 2012

13. Rodrigues, M., L., ve Campos, M.F., "Fingerprinting-based Radio Localization in Indoor Environments Using Multiple Wireless Technologies", 22 ${ }^{\text {nd }}$ PIMRC2011, Toronto, Kanada, 1207-1212, 2011

14. Pei, L., Chen, R., Liu, J., Kuusniemi, H., Tenhunen, T., ve Chen, Y.," Using Inquiry-based Bluetooth RSSI Probability Distributions for Indoor Positioning", Journal of Global Positioning Systems, Cilt 9, No 2, 124-130, 2010.

15. Malekpour, A., Ling, T. C., ve Li W. C., "Location Determination Using Radio Frequency RSSI and Deterministic Algorithm", CNSR 2008 (6th), Kanada, 488-495, 5-8 May1s, 2008.

16. Curran, K., Furey, E., Lunney, T.,, Santos J., Woods, D.,, ve McCaughey, A., "An Evaluation of Indoor Location Determination Technologies", Journal of Location Based Services, Cilt 5, No 2, 61-78, 2011

17. Dawes, B., ve Chin, K.W., "A comparison of deterministic and probabilistic methods for indoor localization", The Journal of Systems and Software, Cilt 84, No 3, 442-451, 2011.

18. Tatar, Y., ve Yıldırım, G., "An Alternative Indoor Localization Technique Based on Fingerprint in Wireless Sensor Networks", International Journal of Advanced Research in Computer and Communication Engineering, Cilt 2, No 2, 1288-1294, 2013.

19. Arya, A., Godlewski, P., Campedel, M., ve Du, C. G., "Radio Database Compression for Accurate Energy-Efficient Localization in Fingerprinting Systems", IEEE Trans. on knowledge and data Engineering, Cilt 25, No 6, 1368-1379, 2013

20. Lin, M.A., Yubin, X., ve Di, W., "A Novel TwoStep WLAN Indoor Positioning Method", Journal of Computational Information Systems, Cilt 6, No 14, 4627-4636, 2010.

21. Rozyyev, A., Hasbullah, H., ve Subhan, F., “ Combined K-Nearest Neighbors and Fuzzy Logic Indoor Localization Technique for Wireless Sensor Network", Research Journal of Information Technology ,Cilt 4, No 4, 155-165, 2012.

22. Milioris, D., Tzagkarakis, G., Papakonstantinou, A., Papadopouli, M., ve Tsakalides, P., "LowDimensional Signal-Strength Fingerprint-based Positioning in Wireless LANs", Ad Hoc Networks, doi:10.1016/j.adhoc.2011.12.006.

23. Jerusha, S., Kulothungan, K., ve Kannan, A., "Location Aware Cluster Based Routing In Wreless Sensor Networks", International Journal of Computer \& Communication Technology, Cilt 3, No 5, 2012 